\title{
The effects of household and workplace smoking restrictions on quitting behaviours
}

\author{
Arthur J Farkas, Elizabeth A Gilpin, Janet M Distefan, John P Pierce
}

\begin{abstract}
Objective-To assess the association of household and workplace smoking restrictions with quit attempts, six month cessation, and light smoking.

Design-Logistic regressions identified the association of household and workplace smoking restrictions with attempts to quit, six month cessation, and light smoking.
\end{abstract}

Setting-Large population surveys, United States.

Subjects-Respondents $(\mathrm{n}=48$ 584) smoked during the year before interview in 1992-1993, lived with at least one other person, and were either current daily smokers or were former smokers when interviewed.

Main outcome measures-The outcome measures were an attempt to quit during the last 12 months, cessation for at least six months among those who made an attempt to quit, and light smoking $(<15$ cigarettes a day).

Results-Smokers who lived (odds ratio $(\mathrm{OR})=3.86 ; 95 \%$ confidence interval $(\mathrm{CI})$ $=3.57$ to 4.18$)$ or worked $(\mathrm{OR}=1.14 ; 95 \%$ CI $=1.05$ to 1.24$)$ under a total smoking ban were more likely to report a quit attempt in the previous year. Among those who made an attempt, those who lived $(\mathrm{OR}=1.65,95 \% \mathrm{CI}=1.43$ to 1.91$)$ or worked $(\mathrm{OR}=1.21,95 \% \mathrm{CI}=1.003$ to 1.45$)$ under a total smoking ban were more likely to be in cessation for at least six months. Current daily smokers who lived $(\mathrm{OR}=2.73,95 \% \mathrm{CI}=2.46$ to 3.04$)$ or worked $(\mathrm{OR}=1.53,95 \% \mathrm{CI}=1.38$ to 1.70$)$ under a total smoking ban were more likely to be light smokers.

Conclusions-Both workplace and household smoking restrictions were associated with higher rates of cessation attempts, lower rates of relapse in smokers who attempt to quit, and higher rates of light smoking among current daily smokers. (Tobacco Control 1999;8:261-265)

Keywords: smoking cessation; smoking restrictions

Recent reviews have shown that environmental tobacco smoke (ETS) places non-smokers at risk of lung cancer, heart disease, and a range of respiratory illnesses. ${ }^{1-3}$ Concerns about ETS have prompted governmental bodies from the local to the national level to adopt laws and regulations to protect non-smokers from ETS. ${ }^{4}$ The primary method of protecting nonsmokers in enclosed work and public areas has been to restrict smoking. If compliance is high, workplace smoking restrictions, especially total bans, are an effective means of protecting nonsmokers from ETS. In addition, workplace smoking restrictions have been shown to increase cessation ${ }^{5-9}$ while decreasing consumption in continuing smokers. ${ }^{5-17}$

Home smoking restrictions, although less studied than workplace restrictions, may have effects similar to those observed for workplace restrictions. When compared to homes with no restrictions, total household bans on smoking were shown to reduce ETS exposure in adolescents who lived with a smoker by $92 \%$, while partial household restrictions (for example, only smoking in certain rooms or at certain times) were shown to reduce ETS exposure by more than $60 \%{ }^{18}$ Data from California suggest that household smoking restrictions may be even more effective in increasing cessation and reducing consumption than workplace restrictions. $^{9}{ }^{19}$

Research has shown that current smokers who reported a quit attempt of a week or longer in the last year are more likely to achieve cessation during the next 18 months than those who did not. ${ }^{20}$ Light smokers, defined as those who consume less than 15 cigarettes a day, are about twice as likely to quit smoking in the next 18 months as those who smoke more heavily. ${ }^{2021}$ Thus any intervention that promotes reduced consumption or increased quit attempt duration is likely to increase the eventual chances of successful cessation. In this article, we compare the relative effectiveness of workplace and household smoking restrictions in promoting quit attempts and successful cessation, using a nationally representative sample of current and recent former smokers.

\section{Methods}

\section{DATA SOURCE}

Data are from three current population surveys (CPS) (September 1992, January 1993, and May 1993) that included a special supplement on tobacco use. The US Bureau of Census continuously conducts the CPS for labour force monitoring, covering the civilian, non-institutionalised population, aged 15 years and older. ${ }^{22}$ The CPS are household surveys that select a stratified probability sample of clusters of households identified from the US Census and other sources. ${ }^{22}$ The CPS design calls for surveying about 56000 households each month by conducting interviews with a knowledgeable household member who responds for all eligible household members. Each household is part of a panel that is interviewed eight times over a 16 month period. All 
respondents to the tobacco use supplements that are reported here were interviewed only once in either September 1992, January 1993, or May 1993. About a quarter of the interviews were conducted in person (first or fifth time in a panel); the remainder were conducted by telephone (second/third/fourth or sixth/seventh/ eighth time in a panel). ${ }^{23}$ For the tobacco use supplement, the CPS attempted three contacts to maximise the proportion of self respondents who completed the supplement. ${ }^{23}$ Response rates for the tobacco use supplement were $88.5 \%, 89.1 \%$, and $86.1 \%$ for September, January, and May, respectively.

The households in the combined sample contained 434161 individuals aged less than one year to 90 years. Of these, 118201 were eliminated because of age (that is, $<18$ years) and 42665 were eliminated because they lived alone. This left an initial sample of 273295 eligible adults, of whom 191068 (69.9\%) were self respondents, $48616(17.8 \%)$ were proxy respondents, and $33611(12.3 \%)$ were non-respondents.

MEASURES OF SMOKING, DEMOGRAPHIC VARIABLES, AND SMOKING RESTRICTIONS Supplement respondents over the age of 17 years who lived with at least one other person ( $\mathrm{n}=191$ 068) were asked, "Have you smoked at least 100 cigarettes in your entire life?" Those who responded "no" were classified as never smokers ( $\mathrm{n}=98$ 048), and those who responded "yes" ( $n=93$ 020) were asked, "Do you now smoke cigarettes every day, some days, or not at all?" Respondents who answered "not at all" were classified as former smokers ( $\mathrm{n}=46492$ ), those who answered "every day" were classified as current daily smokers ( $\mathrm{n}=$ 38 541); those who answered "some days" were classified as occasional smokers $(\mathrm{n}=7812)$ and were not used in the analysis.

Only current daily smokers were asked, "During the past 12 months, have you stopped smoking for one day or longer because you were trying to quit smoking?" The cessation analyses were restricted to current daily smokers $(\mathrm{n}=38541)$ and former smokers $(\mathrm{n}=$ 10 043) who smoked during the previous 12 months. All former smokers and those current daily smokers who answered "yes" were credited with having made an attempt to quit in the previous year. To determine successful cessation, former smokers were asked, "About how long has it been since you completely stopped smoking cigarettes?" Successful cessation was defined as complete abstinence for at least six months. This is an accepted definition of successful cessation. ${ }^{24}$ It should be noted, however, that many of the individuals who had currently quit for less than six months at the time of the survey, especially those who had quit for at least three months, will eventually remain abstinent for longer than six months. Thus the analysis of successful quitting is conservative.

To determine cigarette consumption, current daily smokers were asked, "On the average, how many cigarettes do you now smoke a day?" Current smokers who reported smoking less than 15 cigarettes a day were classified as light smokers, while those who smoked 15 or more cigarettes a day were classified as moderate to heavy smokers.

Data from the standard labour force core questionnaire were used to create dummy variables for the following demographic variables: respondent's sex, age group (18-24, 25-34, $35-44,45-54$, and 55 or more years of age), ethnicity (non-Hispanic white, African American, Hispanic, and other), and level of education (no college $v$ some college), occupation (managerial and professional; technical, sales and administrative support; service; precision production, craft and repair; operators, fabricators and labourers; farming, forestry and fishing; unemployed), family income (less than $\$ 15000, \$ 15000-\$ 30000$, $\$ 30000-\$ 50000, \$ 50000$ or more), the age of the youngest child in the household (none, less than six years, between six and 14 years, between 15 and 17 years), and geographical region (northeast, midwest, south, and west). Data from the tobacco use supplement questionnaire were used to create three additional demographic variables that assessed whether the respondent lived with current smokers, former smokers, and never smokers. Data for the demographic variables may have been derived from proxy reports.

To determine the level of household smoking restriction, self respondents were asked, "Which statement best describes the rules about smoking in your home?" Those who answered "No one is allowed to smoke anywhere" were classified as living under a total ban, while those who answered "Smoking is allowed in some places or at some times" were classified as living under a partial ban. The remaining respondents were classified as living in a household with no smoking restrictions. Employment status and workplace smoking restrictions among self respondents were used to assign each respondent to one of five categories (see below). The workplace policy questions were only asked of a subset of respondents who met the following criteria: (1) they worked in either the public or private sectors, and if they were self employed, they employed other workers; (2) they worked indoors, but not in someone's home. These respondents were asked, "Which of these best describes your place of work's smoking policy for indoor public or common areas such as lobbies, rest rooms, and lunch rooms?" and "Which of these best describes your place of work's smoking policy for work areas?" Those who answered "not allowed in any public areas" and "not allowed in any work areas" were classified as working in a smoke-free workplace, those who only answered "not allowed in any work areas" were classified as working under a work area ban, and the remainder were classified as working under less than a work area ban. Depending on employment status, the rest of the respondents were classified as either other workers or non-workers. 
Table 1 Predictors of making a quit attempt in the last year in the United States, 1992-1993 (CPS tobacco use supplement, 1992-1993; $n=48$ 584)

\begin{tabular}{|c|c|c|c|c|}
\hline Variable & $n$ & $\begin{array}{l}\% \text { Quit } \\
\text { attempt } \dagger\end{array}$ & $\begin{array}{l}\text { Adjusted } \\
\text { OR } \ddagger\end{array}$ & $C I \S$ \\
\hline \multicolumn{5}{|l|}{ Live with a smoker } \\
\hline No & 26355 & 52.1 & 1.00 & - \\
\hline Yes & 22229 & 37.7 & $0.77^{\star}$ & 0.72 to 0.82 \\
\hline \multicolumn{5}{|c|}{ Live with former smoker } \\
\hline No & 37755 & 42.7 & 1.00 & - \\
\hline Yes & 10829 & 55.6 & $1.24^{\star}$ & 1.15 to 1.32 \\
\hline \multicolumn{5}{|c|}{ Live with never smoker } \\
\hline No & 13348 & 43.3 & 1.00 & - \\
\hline Yes & 35236 & 46.3 & 1.00 & 0.92 to 1.08 \\
\hline \multicolumn{5}{|c|}{ Home smoking ban } \\
\hline None & 28732 & 35.4 & 1.00 & - \\
\hline Partial & 12734 & 52.4 & $1.83^{\star}$ & 1.72 to 1.93 \\
\hline Total & 7118 & 71.8 & $3.86^{\star}$ & 3.57 to 4.18 \\
\hline \multicolumn{5}{|l|}{ Work smoking ban } \\
\hline$<$ Work area & 9230 & 43.6 & 1.00 & - \\
\hline Work area & 4695 & 44.6 & 1.04 & 0.94 to 1.14 \\
\hline Smoke free & 7871 & 51.0 & $1.14^{\star}$ & 1.05 to 1.24 \\
\hline Other workers & 6170 & 44.0 & $1.11^{\star}$ & 1.01 to 1.21 \\
\hline Not working & 20618 & 44.9 & 1.01 & 0.93 to 1.10 \\
\hline
\end{tabular}

† Weighted percentages.

¥ Odds ratios adjusted for sex, age, ethnicity, education, income, occupation, region, age of youngest child in the household, and the other variables in the table.

SCI $=95 \%$ confidence interval.

${ }^{\star} \mathrm{p}<0.05$.

STATISTICAL METHODS

The analyses of smoking behaviour included only persons who were self respondents. The public use data files for these three surveys, include a weighting variable for self respondents, so population estimates can be computed. The weights are computed to be consistent with 1990 US Census totals based on state population, and they are representative of the US population by sex, age, and race/ethnicity distributions. All percentages reported are weighted percentages computed using the weighting variable. Variance estimates were inflated by a factor of 1.29 (design effect) for computation of 95\% confidence intervals (CI). The design effect arises from the sampling design and its deviation from a simple random sample.

A series of multiple logistic regression analyses was used to examine the association between smoking behaviour variables (dependent variables in the analyses) and smoking

Table 2 Successful 6+ month cessation in smokers who made a quit attempt in the last year (CPS tobacco use supplement, 1992-1993; $n=22$ 079)

\begin{tabular}{|c|c|c|c|c|}
\hline Variable & $n$ & $\%$ Quit $†$ & $\begin{array}{l}\text { Adjusted } \\
\text { OR } \ddagger\end{array}$ & $C I \rrbracket$ \\
\hline \multicolumn{5}{|l|}{ Live with smoker } \\
\hline No & 13770 & 13.3 & 1.00 & - \\
\hline Yes & 8309 & 8.5 & $0.72^{\star}$ & 0.62 to 0.83 \\
\hline \multicolumn{5}{|c|}{ Live with former smoker } \\
\hline No & 16044 & 10.2 & 1.00 & - \\
\hline Yes & 6035 & 15.1 & $1.29^{\star}$ & 1.12 to 1.48 \\
\hline \multicolumn{5}{|c|}{ Live with never smoker } \\
\hline No & 5804 & 11.8 & 1.00 & - \\
\hline Yes & 16275 & 11.4 & 0.98 & 0.82 to 1.17 \\
\hline \multicolumn{5}{|c|}{ Home smoking ban } \\
\hline None & 10163 & 9.0 & 1.00 & - \\
\hline Partial & 6730 & 11.4 & $1.20^{\star}$ & 1.05 to 1.38 \\
\hline Total & 5186 & 16.3 & $1.65^{\star}$ & 1.43 to 1.91 \\
\hline \multicolumn{5}{|l|}{ Work smoking ban } \\
\hline$<$ Work area & 4005 & 10.4 & 1.00 & - \\
\hline Work area & 2094 & 9.7 & 0.93 & 0.73 to 1.18 \\
\hline Smoke free & 3982 & 13.4 & $1.21^{\star}$ & 1.00 to 1.45 \\
\hline Other workers & 2707 & 10.3 & 1.07 & 0.86 to 1.33 \\
\hline Not working & 9291 & 12.0 & 1.14 & 0.94 to 1.39 \\
\hline
\end{tabular}

† Weighted percentages.

$\ddagger$ Odds ratios adjusted for gender, age, ethnicity, education, income, occupation, region, age of youngest child in the household, and the other variables in the table.

$\int \mathrm{CI}=95 \%$ confidence interval.

${ }^{\star} \mathrm{p}<0.05$. restrictions in the workplace and home and household composition (living with a non-smoker, a former smoker, or a current smoker). The logistic analyses were adjusted for the respondent's sex, age group, ethnicity, level of education, occupation, family income, age of the youngest child in the household, and geographical region. One multiple logistic regression was conducted to identify the associations of household composition and workplace and home smoking restrictions, with a report of a quit attempt in the past year. A second multiple logistic regression, nested within the first analysis, was conducted on the smokers who made a quit attempt in the previous year to identify the association of household composition and smoking restrictions on successful quitting ( $\geqslant 6$ months). A third multiple logistic regression, also nested within the first analysis, was conducted on the current daily smokers to identify the association of household composition and smoking restrictions on light smoking.

\section{Results}

EFFECT OF WORK AND HOME SMOKING

RESTRICTIONS ON QUIT ATTEMPTS

Table 1 shows the likelihood that a smoker reported an attempt to quit in the previous 12 months as a function of home and work smoking restrictions and household composition, adjusted for demographic variables (sex, age group, ethnicity, level of education, occupation, family income, age of the youngest child in the household, and geographical region) and the other variables in the table. Smokers who worked in a smoke-free workplace (odds ratio $(\mathrm{OR})=1.14)$ were more likely to report a quit attempt in the previous year than those who worked indoors with less than a work area ban. Similarly, smokers who lived under a partial home smoking ban $(\mathrm{OR}=1.83)$ or a total home smoking ban (OR $=3.86)$ were more likely to report a quit attempt in the previous year than those who did not. In addition, smokers who lived with a former smoker (OR $=1.24$ ) were more likely to report a quit attempt, while smokers who lived with another smoker $(\mathrm{OR}=0.77)$ were less likely to report a quit attempt.

EFFECT OF WORK AND HOME SMOKING RESTRICTIONS ON SUCCESSFUL CESSATION

Table 2 shows the likelihood that a smoker who attempted to quit in the previous year had achieved successful cessation ( $\geqslant 6$ months) at the time of the interview as a function of home and work smoking restrictions and household composition adjusted for demographics and the other variables in the table. Smokers who made a quit attempt and worked in a smoke-free workplace $(\mathrm{OR}=1.21)$ or who lived under either a partial home smoking ban $(\mathrm{OR}=1.20)$ or a total home smoking ban (OR $=1.65$ ) were more likely to have achieved successful cessation than those who did not. In addition, smokers who lived with a former smoker $(\mathrm{OR}=1.29)$ were more likely to be quit for six months or longer, while those who 
Table 3 Light smoking in continuing smokers (CPS tobacco use supplement, 1992-1993; $n=38$ 541)

\begin{tabular}{|c|c|c|c|c|}
\hline Variable & $n$ & $\begin{array}{l}\% \text { Light } \\
\text { smokers } \dagger\end{array}$ & $\begin{array}{l}\text { Adjusted } \\
\text { OR }\end{array}$ & $C I \S$ \\
\hline \multicolumn{5}{|l|}{ Live with smoker } \\
\hline No & 18677 & 32.8 & 1.00 & - \\
\hline Yes & 19864 & 24.2 & $0.83^{\star}$ & 0.77 to 0.89 \\
\hline \multicolumn{5}{|c|}{ Live with former smoker } \\
\hline No & 31381 & 28.2 & 1.00 & - \\
\hline Yes & 7160 & 29.5 & 0.98 & 0.90 to 1.08 \\
\hline \multicolumn{5}{|c|}{ Live with never smoker } \\
\hline No & 10607 & 24.4 & 1.00 & - \\
\hline Yes & 27934 & 29.9 & 1.04 & 0.94 to 1.15 \\
\hline \multicolumn{5}{|c|}{ Home smoking ban } \\
\hline None & 25424 & 22.6 & 1.00 & - \\
\hline Partial & 9820 & 36.8 & $1.81^{\star}$ & 1.69 to 1.95 \\
\hline Total & 3297 & 45.4 & $2.73^{\star}$ & 2.46 to 3.04 \\
\hline \multicolumn{5}{|l|}{ Work smoking ban } \\
\hline$<$ Work area & 7651 & 25.7 & 1.00 & - \\
\hline Work area & 3858 & 28.6 & 1.10 & 0.97 to 1.24 \\
\hline Smoke-free & 5957 & 36.9 & $1.53^{\star}$ & 1.38 to 1.70 \\
\hline Other workers & 5020 & 21.7 & 0.89 & 0.79 to 1.01 \\
\hline Not working & 16055 & 28.8 & 0.92 & 0.82 to 1.02 \\
\hline
\end{tabular}

† Weighted percentages.

¥ Odds ratios adjusted for gender, age, ethnicity, education, income, occupation, region, age of youngest child in the household, and the other variables in the table.

$\int 95 \%$ confidence interval.

${ }^{\star} \mathrm{p}<0.05$. in smoking behaviours. For example, the nonsmokers in a household may convince the smoker to smoke outside the household and this restriction may later contribute to the smoker's decision to quit. Second, changes in smoking behaviours may lead to the change in smoking restrictions. For example, a smoker may quit, and then, to reinforce the desire not to relapse, the ex-smoker or members of the household agree to adopt the smoking ban. Finally, both quitting and adoption of the home ban may occur simultaneously both for relapse prevention as mentioned above or to eliminate exposure to secondhand tobacco smoke for all household members if other family, friends, or visitors are smokers.

Since household restrictions have only recently become a focus of research interest, no population based prospective studies have been conducted to assess their effects. ${ }^{25}$ In the case of workplace restrictions, where prospective studies have been conducted, the data support a causal relation between the imposition of smoking bans and increased cessation and decreased consumption. ${ }^{5-17}$ We are inclined to think that the level of household smoking restriction may be causally responsible for the increased rate of smoking cessation and the decreased rate of smoking consumption observed in the present study.

Assuming that smoking restrictions do modify smoking behaviours, there are two reasons why smoke-free households may be more effective than smoke-free workplaces in promoting cessation and in reducing consumption. First, the reasons for the adoption of a workplace smoking ban are varied; they include the protection of non-smokers from the hazards associated with exposure to secondhand tobacco smoke, as well as workplace safety (for example, fire prevention) and industrial hygiene (for example, prevention of product contamination). As long as the smoker complies with the policy at work, managers and coworkers may not care if the smoker continues to smoke outside of work. The smoker's situation at home is somewhat different, as the smoker's spouse or children may not be satisfied with compliance with the household smoking ban; instead, they may prefer that the smoker quit altogether. The presence of a home smoking ban may indicate stronger social pressure to quit smoking than does the presence of a workplace smoking ban, and this difference may account for the higher rate of cessation observed for smokers living under a home smoking ban. Second, work bans may also represent less of an impediment to smoking than do home bans. At work, the smoker can smoke immediately before and after work as well as during rest and meal breaks. Compensatory smoking may allow smokers to consume sufficient nicotine to maintain dependency. This may strengthen the ability of temporal cues to elicit the smoking response. ${ }^{26-31}$ Conversely, the requirement to go outside the home to smoke may weaken the ability of various environmental cues (for example, finishing a meal, watching television, talking on the telephone) to elicit the smoking 
response by forcing the smoker to choose between pleasurable activities (for example, smoking $v$ watching a favourite television show). In addition, the requirement to go outside the house to smoke may disrupt smoking by causing the smoker to delay cigarettes (for example, because of the need to dress before going outside to smoke). These differences in household and workplace bans may account for the stronger associations with cessation observed for household bans in the present study.

These data show the need for a large longitudinal study of household smoking restrictions. Only prospective data will resolve the causal ambiguity encountered in the present study. Support for our conclusion that smoke-free households lead to higher rates of successful cessation will provide the public health community with a new weapon in the campaign against tobacco.

Preparation of this article was supported by grant CA 68335 , funded by the National Cancer Institute, National Institutes of Health, and by Grant 6PT-5002, funded by the University of California Tobacco Related Disease Research Program.

1 US Department of Health and Human Services. The health consequences of involuntary smoking: a report of the Surgeon General, 1986. Rockville, Maryland: Public Health Service, Centers for Disease Control, 1986. [DHHS Publication No (CDC) 87-8398.

2 US Environmental Protection Agency. Health effects of passive smoking: assessment of lung cancer in adults and respipassive smoking: assessment of lung cancer in adults and respi-
ratory disorders in children. Final report. Washington, DC:
National Research Council, 1992 .

3 Environmental Tobacco Smoke. Measuring exposure and assessing health effects. Washington, DC: National Academy Press, 1986.

4 US Department of Health and Human Services. Major local tobacco control ordinances in the United States. Smoking and Tobacco Control Monograph No 3. Bethesda, Maryland: Public Health Service, National Institutes of Health, 1993. (NIH Publication No 93-3532.)

5 Stillman FA, Becker DM, Swank RT, et al. Ending smoking at The Johns Hopkins Medical Institutions. $7 A M A$ 1990;264:1565-9.

6 Sorsensen G, Rigotti N, Rosen A, et al. Effects of a worksite nonsmoking policy: evidence for increased cessation. $A m^{f}$ Public Health 1991;81:202-4.

7 Stave GM, Jackson GW. Effect of a total work-site smoking ban on employee smoking and attitudes. F Occupational Med 1991;33:884-90.

8 Kinne S, Kristal AR, White E, et al. Work-site smoking policies: their population impact in Washington State. Am $\mathcal{F}$ cies: their population impact
Public Health 1993;83:1031-3.

9 Pierce JP, Evans N, Farkas AJ, et al. Tobacco use in California. An evaluation of the tobacco control program, 1989-1993. La Jolla: University of California, San Diego, 1994
10 Rosenstock IM, Stergachis A, Heaney C. Evaluation of smoking prohibition policy in a health maintenance smoking prohibition policy in a health mainten

11 Petersen LR, Helgerson SD, Gibbons CM, et al. Employee smoking behavior changes and attitudes following a restrictive policy on worksite smoking in a large company. Public Health Rep 1988;103:115-20.

12 Beiner L, Abrams DB, Follick MJ, et al. A comparative evaluation of a restrictive smoking policy in a general hospital. Am f Public Health 1989;79:192-5.

13 Borland R, Chapman S, Owen N, et al. Effects of workplace smoking bans on cigarette consumption. Am 7 Public Health 1990;80:178-80.

14 Gottlieb NH, Eriksen MP, Lovato CY, et al. Impact of a restrictive work site smoking policy on smoking behavior, attitudes, and norms. F Occup Med 1990;32:16-23.

15 Woodruff TJ, Rosbrook B, Pierce JP, et al. Lower levels of cigarette consumption found in smoke-free workplaces in California. Arch Intern Med 1993;153:1485-93.

16 Brigham J, Gross J, Stitzer ML, et al. Effects of a restricted work-site smoking policy on Brenner H, Bernd F. Smoking regulations at the workplace and smoking behavior: a study from southern Germany. Prev Med 1994;23:230-4.

18 Beiner L, Cullen D, Di ZX, et al. Household smoking restrictions and adolescent exposure to environmental tobacco smoke. Prev Med 1997;26:358-63.

19 Pierce JP, Gilpin EA, Farkas AJ. Can strategies used by statewide tobacco control programs help smokers make
progress in quitting. Cancer Epidemiol Biomarkers Prev 1998;7:459-64.

20 Farkas AJ, Pierce JP, Zhu SH, et al. Addiction versus stages of change models in predicting smoking cessation. Addiction 1996;91:1271-80.

21 Farkas AJ. When does cigarette fading increase the likelihood of future cessation? Ann Behav Med 1999; 21:71-6.

22 Hansen RH. The current population survey: design and methodology. Technical Paper No 40. Washington, DC: US Dept of Commerce, Bureau of the Census, July 1985.

23 Shopland DR. Hartman AM, Gibson JT, et al. Cigarette smoking among US adults by state and region: estimates from the current population survey. $\mathcal{F}$ Natl Cancer Inst 1996;88:1748-58.

24 Velicer WF, Prochaska JO, Rossi JS, et al. Assessing outcome in smoking cessation studies. Psychol Bull 1992;111:23-41.

25 Ashley MJ, Ferrence R. Reducing children's exposure to environmental tobacco smoke in homes: issues and strategies. Tobacco Control 1998;7:61-5.

26 McMorrow MJ, Foxx RM. Nicotine's role in smoking: an analysis of nicotine regulation. Psychol Bull 1983;93:30227.

27 Frederiksen LW, Martin JE, Webster JS. Assessment of smoking behavior. J Appl Behav Anal 1979;12:653-64.

28 Sutton SR, Russell MAH, Iyer $\mathrm{R}$, et al. Relationship between cigarette yields, puffing patterns and smoke intake. Evidence for tar compensation. BMF 1982; 285:600-3

29 Ebert RV, McNabb E, McCusker K, et al. Amount of nicotine and carbon monoxide inhaled by smokers of low-tar, low-nicotine cigarettes. $\mathcal{F A M A} 1983 ; 250: 2840-2$.

30 Bridges RB, Combs JG, Humble JW, et al. Puffing topography as a determinant of smok

31 Diordjevic MV, smoking intensity. Smoke yields of the low-nicotine, low-tar cigarettes. Carcinogenesis 1995;16:2015-21. 